\title{
Deviance from the ethical standard of reporting child sexual abuse in daily newspapers of Bangladesh
}

Asibul Islam Anik (1) ${ }^{1 凶}$, Muhammad Ibrahim Ibne Towhid ${ }^{1,2}$, Syed Shariful Islam ${ }^{1}$, Md. Takit Mallik ${ }^{3}$, Shabnam Azim ${ }^{4}$, Md. Golam Rahman ${ }^{5}$ \& M Atiqul Haque ${ }^{1 \otimes}$

Since child sexual abuse (CSA) is one of the most serious public health issues, how CSA cases and victims are portrayed in the daily newspapers is a major concern to the public health and communication specialists. The purpose of this study was to evaluate the degree of the ethical standard of reporting CSA in Bangladeshi newspapers, as well as to identify the potential risk factors associated with unethical reporting. From January to December 2017, a total of 1093 news stories on CSA were collected from four top circulated Bengali newspapers and two English newspapers of Bangladesh. Berelson's quantitative content analysis approach (only manifest content) was used to analyze these stories. For the coding and analysis purpose, news items (texts and news with photos) of spot news, editorials, and commentaries were included. Chi-square tests were used to evaluate the bivariate association of different case characteristics with unethical reporting, and multivariate logistic regression models were performed to assess the potential risk factors of disclosing the victim's identity and needless detail in the news description. This study revealed that more than $40 \%$ of news stories on CSA cases did not follow the ethical standard of reporting. Episodic CSA cases were more unethically reported in newspapers, compared to the thematic stories ( $42.8 \%$ vs. $11.6 \%$ ). Approximately $37 \%$ of news stories disclosed at least one identifying information of victims (i.e., name, parents' name, family member's name, or school name), and $23 \%$ of stories included sensual and/or excessive description of the event. Our adjusted model showed that victim identifiers were most likely to be reported in news stories when the victim was 13-17 years old (AOR 1.86; $P=0.027$ ), the alleged perpetrator held influential social status ( $A O R$ $2.44, P=0.005$ ), the victim was familiar to the perpetrator (AOR 6.85, $P<0.001$ ), and when public reaction against the CSA incident was reported (AOR 2.75, $P<0.001$ ). In addition, if there was a public reaction to any CSA occurrence, the chances of unnecessary extensive coverage increased by 1.82 times. In conclusion, Bangladeshi newspapers often publish CSA stories without maintaining the ethical standard of reporting and thus ignore child rights.

\footnotetext{
${ }^{1}$ Department of Public Health and Informatics, Bangabandhu Sheikh Mujib Medical University (BSMMU), Dhaka, Bangladesh. ${ }^{2}$ Center for Language Studies (CLS), University of Liberal Arts Bangladesh (ULAB), Dhaka, Bangladesh. ${ }^{3}$ National Institute of Textile Engineering and Research (NITER), University of Dhaka, Dhaka, Bangladesh. ${ }^{4}$ Department of Mass Communication and Journalism, University of Dhaka, Dhaka, Bangladesh. ${ }^{5}$ Department of Journalism and

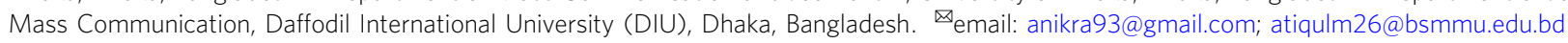




\section{Introduction}

hild sexual abuse (CSA) is a global public health problem with short-term and long-term detrimental health effects (Weatherred, 2017). World Health Organization (Geneva et al., 1999; p. 15) defined CSA as,

"The involvement of a child in sexual activity that he or she does not fully comprehend, is unable to give informed consent to, or for which the child is not developmentally prepared and cannot give consent, or that violate the laws or social taboos of society. Child sexual abuse is evidenced by this activity between a child and an adult or another child who by age or development is in a relationship of responsibility, trust or power, the activity being intended to gratify or satisfy the needs of the other person. This may include but is not limited to: the inducement or coercion of a child to engage in any unlawful sexual activity; the exploitative use of child in prostitution or other unlawful sexual practices; the exploitative use of children in pornographic performances and materials".

Although CSA is a public health concern, it is a hidden form of violence and remains almost under-reported. The overall underreporting rate is mostly related to the culture of shame and social stigma about disclosing CSA (Human Rights Watch, 2013). Newspapers discuss public issues and make people aware of social problems, including child abuse (Saint-Jacques et al., 2012). However, newspapers often fail to address CSA properly and include unnecessary details without maintaining ethical reporting standards (Collings, 2002), which subsequently causes additional shame, and psychological and social burden to the victims. Sometimes, shame produces intense emotions and results in anger, resentment, and resistance, aggression, feelings of pain and discomfort, or even forced to commit suicide (Chilton, 2012; Jones et al., 2010).

Since the 1990s, several guidelines have been proposed for children's news coverage, which was mostly promoted by the International Federation of Journalists (IFJ) and UNICEF, among other organizations around the world (Mike and Norris, 1997). Journalists' organizations from 70 countries first adopted several draft guidelines in 1998 to maintain the highest standards of ethical conduct in reporting children's affairs. Then after several regional conferences and workshops, 11 guidelines were finally adopted by the International Federation of Journalists in 2001 (IFJ, 2001; Mike and Norris, 1997; Peter, 2002). According to the guidelines, journalists should strive for the excellent standard of accuracy and sensitivity when reporting on children involved issues; avoid child damaging programming and images publication with information; avoid stereotypical or sensationalist coverage of child issues; consider the consequences before publishing any children involving material to minimize the harm of children; guard against visually or otherwise identifying children; give children the right of access to media to express their own opinion; ensure independent verification of children provided information without putting them at risk; avoid the use of child sexualized images; use fair, open, and straight forward methods for obtaining pictures with children's or guardian's consent; verify the credentials of any information; and not pay to any children for material regarding their wellbeing or to their parents (Peter, 2002). After that, while reporting child news, the National Center for Injury Prevention and Control (2016), United States, suggested journalists about resisting themselves from using sensationalist language or phrases for news coverage and avoiding the disclosure of victims' identify. In addition, UNICEF (2017) has described that for children's news coverage in the newspapers, standard reporting should ensure safety and privacy (i.e., identity protection), truth-seeking coverage; avoiding indecency, vulgarity, obscenity, sensationalism, and cruelty in news stories; avoiding detailed description of antisocial activities and self-harm or suicide; respecting to diverse values and faiths; avoiding harmful contents; avoiding discrimination or stereotyping; monitoring other child rights; accountability, etc.

\section{Bangladesh legal system: Child sexual abuse and identity disclose}

Although there is no unique definition of CSA in the Bangladeshi legal system, the Domestic Violence (Prevention and Protection) Act, 2010 (Act 58 of 2010) refers to sexual abuse as, "any conduct of a sexual nature that abuses, humiliates, degrades or otherwise violates the dignity of the victim".

Besides, several other Acts and Laws of Bangladeshi legal systems like Bangladesh Penal Code, 1860, The Prevention of Oppression against Women and Children Act, 2000, National Action Plan to Prevent Violence against Women and Children, 2013-2025, Suppression of Immoral Traffic, 1933, and The Child Act, 2013 have stated terminologies in describing sexual abuse which is almost similar to the terms used in WHO definition of CSA. The terms coming from the above-mentioned Acts and Laws to describe CSA are rape, undesirable sexual appeal, establishing sexual relation by using administrative power, making and/or sharing pornography, non-consensual sexual behavior or expression, teasing and passing erotic comments, a proposal for illegal affairs and providing pressure in case of refusal, trying to build a sexual relationship by pretension or false promise, and kidnapping, selling, or buying minors for prostitution. In addition, The Prevention of Oppression against Women and Children Act, 2000, prohibits disclosure of victim's identities in news media while describing CSA stories.

\section{Code of ethics and child sexual abuse: In the context of Bangladeshi journalism}

When reporting on any CSA incidents, journalists should uphold the existing ethical codes and abide by the aforementioned state laws. Bangladesh has a great legacy of journalism, backed up by a strong sense of moral obligation, yet there are no effective codes among most of the journalistic communities, and the existing Press Council Codes appear to be inadequate (Bangladesh Press Council, 2002; UNICEF, 2010a). The Dhaka Union of Journalists (DUJ), one of the local news reporters' associations, has a set of 13 guidelines that solely reflect the safeguarding issues of the union members, but none of these guidelines mention anything about children's coverage. Though similar guidelines can be found within some local journalists' associations across the country, most of the journalists possess a lack of awareness concerning these guidelines (Elahi, 2013; UNICEF, 2010a). On the other hand, the Bangladesh Press Council, a statutory body of Bangladesh, issued a code of conduct (consists of 25 clauses) for newspapers and journalists in 1993 (amended in 2002). But no special guidelines for reporting on children were mentioned in any of the provisions. Since, clauses ' 13 ' and ' 23 ' warned journalists to avoid publishing any vulgar, derogatory, ghastly news and picture (Bangladesh Press Council, 2002), this could have implications for CSA coverage. These phrases, however, are not explicitly directed towards the children. In addition, the baseline study of UNICEF (2010a, 2010b) reported that most of the newspaper agencies of Bangladesh (except, Prothom Alo) do not have their own codes of ethics substantially. 


\section{Literature review}

The reported prevalence of CSA worldwide varies widely due to methodological differences in conducting research (Singh et al., 2014). Barth et al. (2013) estimated the global prevalence of CSA ranging from 8 to 31 percent for girls and 3 to 17 percent for boys. In the South Asian context, 4 to 57 percent of children irrespective of gender are victims of sexual abuse (Choudhry et al., 2018; Government of Pakistan and UNICEF Pakistan, 2017). However, there is limited information about the prevalence of CSA in Bangladesh, while newspapers and organizational reports are the mainstays of information.

News media has a great social responsibility of protecting children's rights while reporting child abusive events. But poor, quick, and unethical reporting on children with the little investigation may entertain or divert the reader from the actual incident; and may generate noise, heat, myths, and stereotypes among the audience (Peter McIntyre, 2002). That is why, media's moral right of free public expression is not unconditional-which is one of the conceptual pillars of the Social Responsibility of the Press (SRP) theory (Christians et al., 2009). In other words, a free press carries a concurrent obligation to be responsible to the public. McQuail (2010) further developed the SRP theory and noted that the media have an inherent responsibility for a democratic society with a compact of social obligations. Since media ownership is the public trust, news media should be truthful, accurate, fail, objective, informative, and relevant. Moreover, media should be free but self-regulated and should follow existing codes of ethics and professional standards, such as the IFJ and UNICEF provided ethical reporting guidelines (IFJ, 2001; McQuail, 2010; UNICEF, 2017). But it is little known to what extent ethical standards of reporting are maintained for CSA news coverage in low-income and middle-income countries (Ho and Chan, 2018). Studies reported that newspapers often publish CSA stories with unnecessary details and mention victim's identifiers such as name, address, etc. (Lonne and Parton, 2014; Niner et al., 2013). In such cases, McQuail (2010) argued that from the perspective of SRP, media obligations for society require the effort of avoiding controversies regarding journalistic performance, such as bias, misrepresentation, invasion of privacy, misinformation, and sensualization of the actual event to excite the greatest number of readers. But all these social responsibilities and codes of ethics are often overridden by news agencies across the world. Jones et al. (2010) found in their study that 37 percent of news articles on CSA in the USA revealed at least one victim's identifier. In most South Asian countries, the actual scenario of unethical reporting of children's news coverage is obscure for the international research community (Goonasekera, 2001). Analyzing some CSA stories reported from several Indian newspapers, it was found that sensitive details like the identity of the victim and the family were unnecessarily published to sensationalize the story (Nair, 2019). A study conducted by UNICEF (2010) revealed that approximately one-fifth of CSA news stories in Bangladeshi newspapers disclosed the victim's identity. However, there has not been any recent comprehensive study to assess how far Bangladeshi newspapers follow the ethical guidelines of reporting.

\section{Theoretical framework}

The newsworthiness of stories, the role of media in covering violence and crime cases, violation of child rights, professional practices, and sources of information-can explain why newspapers report CSA stories without maintaining an ethical standard.

News selection is a complex process and is mainly shaped by socio-cultural, economic, political, organizational, and psychological contexts (Schwarz, 2006). According to some journalism scholars, news selection and construction are mainly wrapped up by several approaches, where newsworthiness is one of them (Caple, 2018; Strömbäck et al., 2012). Newsworthiness can be described as how journalists value each news story based on their political importance, social effect, novelty, pathos, or anticipation of public interests (Hodgkiss, 2017). Different studies have found that worthiness of CSA stories increase especially when the alleged perpetrator(s) hold high social responsibilities, such as police officers, clergy members, teachers, and celebrity; the victim had a familial relationship with the offender; additional violence or homicide, sensational crime activities or multiple victims (Cheit, 2003; Schildkraut, 2017; Wong and Lee, 2021).

Reporting on CSA in the media is not dissimilar to reporting on general violence and crime in society (Merchant, 2010). International literature depicted that there are similar trends in news reporting on CSA to what has been observed in the Bangladeshi news media. Studies from the USA, Canada, New Zealand, Australia, and India disclosed that for most of the time public is informed about CSA through media reporting (Human Rights Watch, 2013; Merchant, 2010; Saint-Jacques et al., 2012). Such media exposure to educate and inform the readers is usually seen as one of the easiest and cost-effective techniques for preventing and raising awareness against the CSA (Miller-Perrin and Perrin, 2012). While covering crime stories, media manifest their take on the criminal issues and can influence the public by the manner of conveying information and influencing the public realization and reaction against the issue. Sensational reporting of CSA by newspapers may become 'entertainment' for the reader due to the horrible and 'different' nature of the abuse in addition to providing unnecessary information; that is uncommon to the reports of other child abuses (Merchant, 2010). That is why Barrister Paul Treadwell (2006) concurred that media have a great responsibility to maintain the ethical standard of reporting on CSA cases so that the public can gain a better understanding of what CSA means, and how dangerous and horrible it is for a society.

But United Nations Convention on the Rights of the Child (UNCRC) (UNICEF, 2017) outlined that newspapers tend to cover children's issues focusing on sensational matters, ignoring the broad array of topics like maintaining confidentiality. Hodgkiss (2017) found journalists and news agencies have a perception that the portrayal of child news in a sensational way might fulfill the public interest, which consequently influences commercial imperatives, and circulation and readership ratings. According to UNCRC, publishing the identities of child victims in mass media is a violation of child rights (UN General Assembly, 1989). Alike developed countries, publishing a victim's identity in news media is legally prohibited in countries of South Asia and violation of such act is a punishable offense (Protection of Children from Sexual Offences Act, 2012-India; Electronic Media Code of Conduct, 2015-Pakistan). It is admissible that most governments across the world have put a great emphasis on protecting child rights conserving victim's privacy and identity from being published publicly. Nevertheless, publishing a victim's identity despite having legal guidelines indicates news media's ignorance towards child rights.

Media professionals have a common tendency to sensationalize and highlight violence in the coverage, especially when it is regarding children (Foley et al., 2008). In 2010, UNICEF conducted a baseline survey in Bangladesh where it disclosed that codification of journalism ethics or of upholding ethical codes is a rare practice among media professionals. Though the gatekeepers and reporters generally understood the ethical parameters in the context of children, when it comes to practicing, the findings indicated that there were some significant gaps in translating 
ethical perceptions into practice (UNICEF, 2010a). This study referred that the reporters and gatekeepers possessed a considerable misunderstanding about what a code of conduct or ethics is. On the other hand, Elahi (2013) surveyed 333 media professionals of Bangladesh, where nearly half of them (46\%) believed it is acceptable to receive gifts (or money) from the sources (of information); and according to them, it was a common practice and harmless. One section of journalists did not even know that paying or receiving gifts to a source was ethically wrong. In the same survey, about 42 percent of professionals said they would secretly record a conversation and would not identify themselves as media professionals to obtain truthful information from a source. In addition, sometimes journalists report a piece of news without mentioning the source(s) of information. Occasionally news coverage violated ethical standards since reporters used unnamed or indistinct sources, and editors or gatekeepers could not verify the source (Jones et al., 2010).

Bangladesh is one of the signatory countries to ratify the UNCRC where it was stated that under 18 should be the cut-off age for consideration of general issues such as rights-based approaches to media coverage and the effect of media on children (UNICEF, 2010a). Again, according to UNCRC, journalism is ethically bound to facilitate child rights by protecting children's privacy, security, both physical and mental health, and social welfare. So, after the 30 years of UNCRC, how the privacy rights of children are protected and how CSA incidents are portrayed in newspapers in the context of Bangladesh-still demand a profound investigation for the international community. However, this study primarily focused on the existing practice of ethical coverage to sexually abused children under the age of 18 .

On the other hand, since CSA is one of the major public health problems, how CSA incidents and victims are portrayed in newspapers is a great concern to the public health and communication experts. Facts like-how society perceives CSA, and how the corresponding authorities can change institutional policies, and handle CSA cases and legislations-mostly depend on ethical journalism in media (Weatherred, 2017). In addition, to minimize the potential harm to the CSA victims from newspapers, ethical reporting and practices must be ensured and upheld. But there is hardly any comprehensive research work depicting the present scenario of ethical standards on CSA news coverage in Bangladeshi newspapers. Moreover, potential risk factors associated with such unethical coverage are still obscure. Addressing these knowledge gaps, this study aimed to examine the extent of the ethical standard of reporting CSA in Bangladeshi newspapers and to identify the associated risk factors of unethical reporting.

\section{Methodology}

Berelson's quantitative content analysis technique (only manifest content) was used in this study to analyze newspaper stories (Bengtsson, 2016). News stories on CSA published in six national-coverage daily newspapers from January to December 2017 were collected. The inclusion criteria of newspapers were broadsheet publications with at least 16 pages per issue. Four highly circulated Bengali newspapers ("Prothom Alo", "Daily Kaler Kantha", "Daily Jugantor", and "Daily Ittefaq") and two English newspapers ("The Daily Star" and "Daily Sun") of Bangladesh were selected for data collection (Department of Films and Publications, 2016).

Content analysis and coding. News items (texts and news with photos) of spot news (immediate and up to date), editorials, and commentaries were considered for coding and analysis. These news items and captions of the photos were scanned thoroughly and then selected for analysis in terms of the merit of their content relating to their relevance to the topic of sexual abuse of a child or children younger than 18 years old. But news stories with very short information (i.e., less than two to three sentences long) and/or the photo caption without highlighting CSA were excluded from this study. Finally, a total of 1093 news stories were coded for analysis after excluding follow-up news stories $(n=128)$, and duplicate news stories $(n=113)$. In order to include the primary events only, follow-up stories were excluded. Duplicate news stories, i.e., articles with the same stories printed in sampled newspapers, were eliminated. A simple random sampling process (lottery method) was followed to identify unique news articles from duplicate stories.

Details of the newspaper stories (texts) and the photos (captions) were documented in a predesigned data (code) collection sheet for analysis. Authors of this study developed the code-sheet based on the empirical studies (Haque et al., 2020; Jones et al., 2010; Weatherred, 2017), existing code of conduct (Bangladesh Press Council, 2002), and guidelines for reporting on children (UNICEF, 2010a, 2017), and expert opinions. This code-sheet was divided into three parts. The first part included socio-demographic information of the CSA victim (age, gender, occupation) and the alleged perpetrator (age, gender, relation to the victim, number of perpetrators, occupation, and social status). The second part documented several characteristics of the event, i.e., story frame, fatality, place of occurrence, presence of news source, and public reaction. And the third part consisted of several criteria indicating ethical reporting of the story. The third part of the code-sheet, i.e., criteria for ethical reporting considered in this study, has been tabulated in Supplementary Information S1.

Two coders, one mass media graduate, and the first author of this article were assigned for manual coding. The coders were trained by the last author of this article. An iterative process of coding was used until reaching satisfactory inter-coder reliability. As a final test, a subset of the sample $(n=100)$ other than the selected news articles of this study, was given to each of the coders for independent coding. Krippendorff's alpha inter-coder metric was adopted to evaluate the level of agreement (above 0.80). Inter-coder reliability was estimated for each of the categories and was found high $(84.0 \%-100.0 \%)$. The final coding procedure was performed in the same setting and to remove ambiguity, frequent consultations were made within the research team. In addition, after completing the coding procedure, two mass media experts randomly rechecked the coding for data purification.

\section{Operational definitions and coding procedures}

Child. Anyone under the age of 18 was considered as a child (UNCRC, 1989). News stories having the term 'shishu' (baby or child), 'balok-balika' (pre-adolescent), and 'kishore-kishori' (adolescent) without mentioning the age directly were also considered child-related news as these terms indicate different developmental stages of a child in Bengali culture (Blanchet, 1996). Victims were confirmed as children by their mentioned age of schooling or educational status if any other information could not be found.

Sex. When the sex of the victim and perpetrator was not specifically mentioned, it was identified by their names. The cultural and language context of Bangladesh easily allows identification of their gender by a person's name.

Child sexual abuse. The terms mentioned in the Bangladeshi legal system on CSA were adopted in this study to describe the different types of sexual abuse. 
Unethical reporting in newspapers. Disclosure of victim's identifiers and/or reporting unnecessarily detailed descriptions of the CSA events were considered as 'unethical reporting' in this study. The victim's identity was considered 'disclosed' if the newspaper published-the name of the victim, the name of the victim's parents or any family member, and/or the name of the victim's educational institutions. Unnecessary details and information of CSA incidents, such as ghastly, violent, and sensualized description of the event; description involving video with sexual content; and any information or link regarding the shared and uploaded contents in social media were also considered as unethical reporting (see Supplementary Information S1).

Independent variables. The victim's occupation was categorized into three types: children studying in the general education system of Bangladesh, madrasah students, and others (domestic worker, day labor, workers, etc.). The occupation of alleged perpetrators was categorized into the teacher (both general and madrasah), student (general and madrasah), manual labor (transport workers, labors, farmers, etc.), businessperson (large and small businessmen, shopkeepers), politician, service holder (govt. and non-govt. staffs, doctors, engineers, security personnel, law enforcers, etc.), and others (retired, unemployed, vagabond, traditional healer, emigrants, etc.). Based on occupation, perpetrators' social status was categorized into a local influential person (teachers, political figures, religious leaders, and service holders), and other (manual labors, students, businessmen, security personnel, transport workers, non-govt. staff, and others, etc.).

The relationship status between alleged perpetrators and victims was classified as within family relationship (biological parents and other family members), known but not within a family relationship (person with a romantic relationship, classmate, teacher, neighbor, employer or colleague, and another local known person), and unknown (where any specific relationship status was not mentioned). Perpetrator's relationship with the victim' was further dichotomized as 'known' (combining 'family relationship' and 'known but non-family relationship') and 'unknown'.

Based on the empirical literature (Dorfman et al., 2005; Major, 2009; Mejia et al., 2011), news stories were framed as either episodic (i.e., framed around a singular person or event) or thematic (i.e., focused on the broader context surrounding the news event, or opinion). More specifically, episodic news coverage provides the readers a little insight or information into the larger social circumstances contributing to individual situations and problems. On the other hand, by underscoring broader trends and social conditions, thematic (or, opinion-based) coverage generates a sense of shared responsibility and encourages collective public action in the society. If the news stories reported any fatality cases due to/during the CSA incident, then the variable 'reported victim fatality' was coded as 'yes'; otherwise, 'no'. The 'place of occurrence', where the incident was primarily reported to have occurred, was initially divided into five categories as victim's home, perpetrator's home, controlled place (educational or religious institute, workplace, hospital or clinic, residential hotels, shops, etc.), barren place (gardens, farmlands, abandoned houses, etc.) and street. If the alleged perpetrator was either any of the parents or family members and the incident took place where the victim was residing, then the place of occurrence was included in 'victim's home'. 'Place of occurrence' was further classified as 'others' (combining victim's home, perpetrator's home, street, and barren places) and 'controlled place'. If the information source of the story was directly reported or identifiable, then the 'presence of news/information source' was coded as 'yes'; for unnamed or indistinct news sources, 'no/ indistinct'. When any report included any sort of 'public reaction' (assembled protest, human chain or mass procession against the specific CSA events, and local collaboration to either capture the perpetrator or help the victim), the variable was coded as 'yes', otherwise 'no'.

Statistical analysis. Continuous variables were analyzed by estimating measures of central tendency (median) with maximum and minimum values; categorical variables were analyzed by estimating frequency and percentage. Chi-square tests were used to identify the bivariate association of different case characteristics with unethical reporting in episodic and thematic story frames and stories with fatality. Multivariate logistic regression models were used to assess the association of different covariates with disclosed victim's identity and unnecessary detail of news description. Covariates that showed significant association with the dependent variables in the bivariate model were included in logistic regression models to find out both unadjusted and adjusted odds ratios with a 95 percent confidence interval. The significant level was set at $P<0.05$. No multicollinearity among variables was found $(\mathrm{VIF}<5)$. The values of Nagelkerke R-square in both adjusted models (disclosing victim's identity and providing unnecessary descriptions) were 0.27 and 0.14 and considered as acceptable (Itaoka, 2012). Data were recorded and analyzed using Statistical Package for Social Sciences (SPSS) version 25.0 .

Ethical considerations. The data collection technique was devised in a workshop comprising experienced mass media and journalism researchers, lawyers, epidemiologists, and public health researchers at Bangabandhu Sheikh Mujib Medical University (BSMMU), Bangladesh. The area of research was news stories of the newspapers reported with public and open access. The population was not human subjects, although individuals were mentioned in the news stories. This type of research does not require formal ethical clearance.

\section{Results}

Socio-demographic characteristics of victims and alleged perpetrators. The majority of the CSA-reported victims were female (97\%), school students (about 80\%), and single in number (about $85 \%)$, whereas almost all the alleged perpetrators were male (more than 98\%) (Table 1). The median (minimum-maximum) age of the victim was $13.00(3.00-17.00)$ years, whereas seven out of 10 alleged perpetrations were less than 30 years old. Most of the victims were within a known relationship with the perpetrator where approximately four percent were within a blood relationship and about 65 percent were known but not within a blood relationship.

Characteristics of news stories. Nine out of 10 news stories followed the episodic story frame. 11 percent of CSA stories reported victim fatality. Approximately one-fifth of CSA events occurred in controlled places like academic institutions, workplaces, hospitals, or residential hotels. About 16 percent of news stories had no or indistinct source of news information (Table 1.).

The ethical standard of reporting CSA stories. Four out of 10 CSA news stories had no ethical standard of reporting (Table 1). Table 2 shows that approximately 37 percent of stories revealed victims' identities. The notable victim's identifiers were the name of their educational institutions (about 29\%) with or without mentioning the grade, and the name of the parents (11\%). But about 10 percent of news stories directly mentioned the victim's name. On the other hand, more than 23 percent of the CSA stories disclosed unnecessary details of the abusive events. 


\section{Table 1 Characteristics of CSA cases reported in daily} newspapers of Bangladesh, $2017(N=1093)$.

\begin{tabular}{lll} 
Case characteristics & Frequency (\%) & $\begin{array}{l}\text { Ethical standard of } \\
\text { reporting (\%) }\end{array}$ \\
\cline { 2 - 2 } & Yes $\quad$ No \\
\hline
\end{tabular}

Socio-demographic context (victim)

Sexa

$\begin{array}{llll}\text { Female } & 1121(97.0) & 56.4 & 43.6 \\ \text { Male } & 35(3.0) & 81.8 & 18.2\end{array}$

Age $(n=838)^{b}$

Younger child ( $\leq 12$ years old)

Male $\quad 13(1.6) \quad 76.9$

Female $\quad 392(46.8) \quad 60.1 \quad 39.9$

Older child (13-17 years old)

Male

8 (1.0)

Female

$425(50.6)$

80.0

49.8

20.0

Occupation $(n=825)^{c}$

School student

$\begin{array}{lll}659(79.9) & 50.2 & 49.8\end{array}$

Madrasah student

$139(16.8)$

Others (domestic worker, 27 (3.3)

67.9

67.7

day labor, workers, etc.)

Number of victims

$\begin{array}{llll}\text { Single } & 932(85.3) & 57.2 & 42.8\end{array}$

$\begin{array}{llll}\text { Multiple } & 161(14.7) & 75.8 & 24.2\end{array}$

Socio-demographic context (alleged perpetrator)

Sex ${ }^{d}$

$\begin{array}{llll}\text { Male } & 1542(98.2) & 56.6 & 43.4\end{array}$

$\begin{array}{llll}\text { Female } & 28(1.8) & 75.0 & 25.0\end{array}$

Age $(n=438)^{\mathrm{e}}$

$\leq 30$ years

$>30$ years

$310(70.8) \quad 61.6 \quad 38.4$

Occupation $(n=415)^{f}$

Teacher

$128(29.2)$

50.0

50.0

Manual labor

$93(22.4)$

$58(14.0)$

Businesspersons

$48(11.5)$

$32(7.7)$

Politicians

$24(5.8)$

Service holder

$24(5.8)$

Others

$136(32.8)$

Number of perpetrator $(n=980)$

Single $\quad 710(72.4)$

Multiple

$270(27.6)$

Perpetrator's social status $(n=404)^{g}$

Others

$257(63.6)$

Local Influential

$147(36.4)$

person

Perpetrator's relationship with victim ${ }^{\text {h }}$

Family relationship $\quad 40$ (3.7)

Known (non-family 705 (64.5)

relationship)

Unknown

$348(31.8)$

52.7

64.8

51.1

56.7

45.5

54.5

57.4

59.4

50.7

56.8

53.7

47.3

35.2

48.9

43.3

54.5

45.5

42.6

40.6

49.3

43.2

46.3

Characteristics of news stories

Story frame

Episodic

Thematic

998 (91.3)

95 (8.7)

57.2

88.4

42.8

Reported victim fatality

No

$970(88.7)$

123 (11.3)

Yes

Place of occurrence $(n=890)$

Others

$713(80.1)$

Control places

177 (19.9)

58.0

74.8

42.0

25.2

55.7

44.3

Presence of news/information source

$$
\begin{array}{ll}
\text { No or indistinct } & 173(15.8) \\
\text { Yes } & 920(84.2)
\end{array}
$$

57.6

42.4

$62.4 \quad 37.6$

$59.5 \quad 40.5$

Public reaction

No

$561(51.3)$

\begin{tabular}{|c|c|c|c|}
\hline \multirow[t]{2}{*}{ Case characteristics } & \multirow[t]{2}{*}{ Frequency (\%) } & \multicolumn{2}{|c|}{$\begin{array}{l}\text { Ethical standard of } \\
\text { reporting }(\%)\end{array}$} \\
\hline & & Yes & No \\
\hline Yes & $532(48.7)$ & 58.1 & 41.9 \\
\hline Total & & 59.9 & 40.1 \\
\hline \multicolumn{4}{|c|}{$\begin{array}{l}\text { N, total number of news stories; n, number of observations. } \\
\text { aA total of } 1156 \text { victim's gender identity was reported in } 1093 \text { news articles. } \\
\text { bIn a total of } 785 \text { news stories (data reported up to } 3 \text { victims per article), a total of } 838 \text { victims' } \\
\text { age were reported, of the } 21 \text { were male and } 817 \text { were female victims. } \\
\text { 'Total } 825 \text { victim's occupations were reported in } 700 \text { news articles (data reported up to } 3 \\
\text { victims per article). } \\
\text { dTotal } 974 \text { news stories provided the gender of } 1570 \text { perpetrators. } \\
\text { e' } \text { 'n total } 354 \text { news stories (data reported up to } 3 \text { perpetrators per article), a total of } 438 \\
\text { perpetrators' age were reported. } \\
\text { fIn total } 404 \text { news stories (data reported up to } 3 \text { perpetrators per article), total } 415 \text { perpetrator's } \\
\text { occupation was reported. } \\
\text { gPerpetrators' social status was reported in a total of } 404 \text { news stories. } \\
\text { hFor multiple perpetrators, at least one known perpetrator was included in the known category, } \\
\text { otherwise in 'unknown'. }\end{array}$} \\
\hline
\end{tabular}

61.7
Table 1 (continued)

Most of these stories (18.3\%) contained ghastly, horrible, or sensual descriptions of the sexual events (Table 2).

The ethical standard of reporting was violated more while stories were covering CSA incidents of school students and older female children (Table 1). On the other hand, violation of standard reporting was comparatively more prevalent among these stories where alleged perpetrators were multiple, belonged to older age group, and had a familial relationship with the victim(s). In addition, episodic CSA cases were more unethically reported in newspapers, compared to the thematic stories ( 42.8 vs. $11.6 \%)$.

Some examples of the newspaper story text (reviewed in this study), that violated the ethical standard of reporting, had been tabulated in Table S2.

The proportion of unethical reporting in episodic and thematic coverage, and stories with victim fatality. Victim's identity and unnecessary descriptions were highly reported in episodic CSA stories, compared to the thematic coverage, and stories with victim fatality (Table S3). In the episodic CSA stories, identity discloses and unnecessary descriptions were significantly more observed for older children ( $47.4 \%$ vs. $36.8 \%, P(\chi 2)=0.002$; and $27.8 \%$ vs. $22 \%, P(\chi 2)=0.039$, respectively) than the younger ones. The identifying information was more significantly reported to male victims than the females $(72.7 \%$ vs. $38.2 \%$, $\left.P\left(\chi^{2}\right)=0.001\right)$. In addition, newspapers disclosed victims' identity more significantly in the cases of local influential $(64.6 \%$ vs. $42 \%, P(\chi 2)<0.001)$, and known perpetrators $(42.6 \%$ vs. $30.2 \%, P(\chi 2)<0.001)$, than the others and unknown perpetrators. The identity was disclosed by 20 percent when there was any public reaction against the abuse (i.e., $50.0 \%$ vs. $30.1 \%$ ). On the contrary, no significant unethical reporting was found in the stories with fatalities, except the cases of perpetrator-victim relationships (identity disclose, known $94.6 \%$ vs. unknown $31.3 \%)$. However, in total, episodic coverage significantly disclosed the victim's identity $(39.4 \%$ vs. $12.8 \%)$ and reported unnecessary description (24.4\% vs. $10.5 \%)$, compared to the thematic coverage.

Risk factors of unethical reporting. Because of the plethora of unethical reporting in episodic CSA cases, only episodic stories were considered for comparing the likelihood of victim's identity disclosure and unnecessary details in CSA stories by different case characteristics (Table 3). In the unadjusted association, all the selected case characteristics (i.e., victim's age, 
Table 2 Unethical reporting in daily newspapers of Bangladesh, $2017(N=1093)$.

\begin{tabular}{|c|c|c|c|}
\hline Unethical reporting & Classification & $\begin{array}{l}\text { No } \\
n(\%)\end{array}$ & $\begin{array}{l}\text { Yes } \\
n(\%)\end{array}$ \\
\hline \multirow{3}{*}{$\begin{array}{l}\text { Victim's identifying informationa (disclosed in } 37.1 \% \\
\text { news stories) }\end{array}$} & Victim's name directly mentioned & $987(90.3)$ & $106(9.7)$ \\
\hline & Parents' name (father, mother, or both) & $973(89.0)$ & $120(11.0)$ \\
\hline & Name of victim's educational institutes & $779(71.3)$ & $314(28.7)$ \\
\hline \multirow{2}{*}{$\begin{array}{l}\text { Unnecessary detailed description of the abusive event } \\
\text { (reported in } 23.2 \% \text { news stories) }\end{array}$} & Ghastly, horrible, or sensational description & $893(81.7)$ & $200(18.3)$ \\
\hline & Description involving video, photography, pornography & $1039(95.1)$ & $54(4.9)$ \\
\hline
\end{tabular}

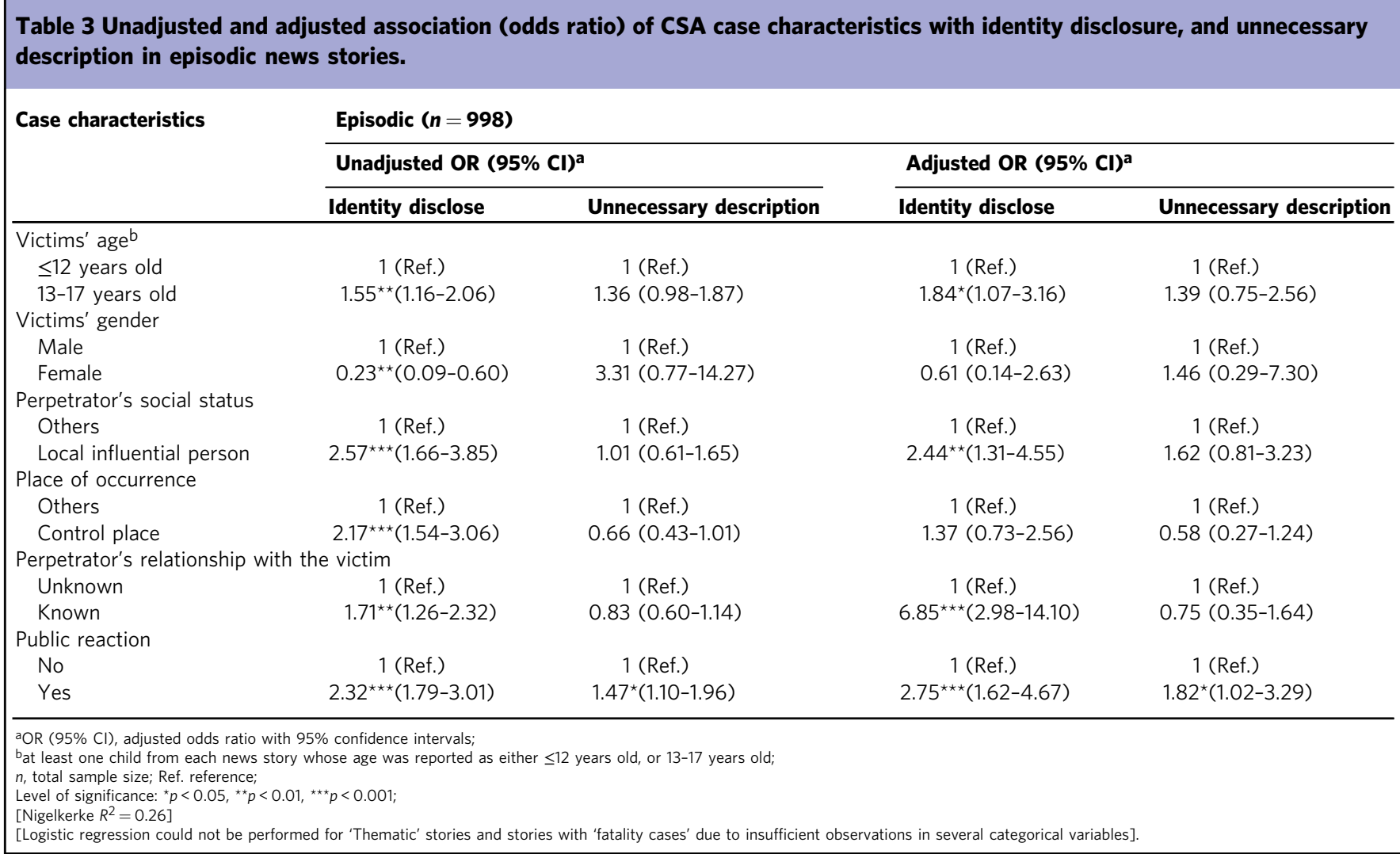

gender, relationship with the perpetrator; perpetrator's social status; place of occurrence; and public reaction) showed significant association with victim's identity disclosure, and only the public reaction showed a positive association with unnecessary description. However, after adjusting all other covariates, the adjusted result indicated that the possibility of disclosing the victim's identity was 1.84 times higher for the older child victims (AOR 1.86; $P=0.027$ ) than the younger ones. In addition, there were positive and significant associations of revealing victim's identity with perpetrator's influencing social status (AOR 2.44, $P=0.005$ ), known relationship with the victim (AOR 6.85, $P<0.001$ ), and presence of public reaction (AOR 2.75, P<0.001). On the other hand, the likelihood of reporting unnecessary descriptions in CSA stories increased 1.82 times when there was any public reaction against the abusive events (AOR 1.82, $P=0.043$ ).

\section{Discussion}

In our review of newspaper coverage, 40 percent of the news stories on CSA did not adhere to the ethical standard of reporting. UNICEF (2010a, 2010b) elicited a similar conclusion about 10 years ago, where it exposed that a broad range of Bangladeshi newspapers not only violated journalistic ethics of child protection in vulnerable situations but also breached existing legislative safeguards for children (UNICEF, 2010b). Studies from around the world reported that newspapers often tend to report sexual abuse unethically (Ayre, 2001; Ho and Chan, 2018). According to the study of Maharani (2018), Indonesian news media often violate the journalistic code of ethics by revealing sexual victims' identities, depicting raunchy and sadistic details of the assaults. When reporting on CSA stories in Thailand, the news media frequently discloses the victim's privacy and uses improper, sensational, and provocative language (UNICEF, 2014). 
The reasons behind the media reporting of CSA unethically may be due to the newsworthiness of the stories. Nair (2019) stated that a sensationalized news portrayal of abusive incidents piques public attention. Furthermore, when it comes to the CSA, such sensationalized descriptions are more commonly reported in the media (Furedi, 1997). The commercial policies of news organizations may provoke the journalists for unethical reporting on CSA cases on a regular basis. Chermak (1994) illustrated that newspapers describe crime news elaborately, mostly motivated by the concept of the public's unquenchable need for thorough explanations of crime stories. As a result, newspapers tend to report extensive crime stories to accomplish their business objectives and increase their circulation. Jaggi and Majumdar (2009) found that Indian news media sensationalize news stories and 85 percent of news channels distorted facts solely for gaining their popularity.

Another factor for unethical CSA reporting by the newspapers could be a lack of knowledge about children's rights. In Bangladesh, despite having provision not to disclose victim's identity in the Prevention of Oppression against Women and Children Act-2000, 37 percent of news reports on CSA of this study revealed their identity. Again, due to the lack of substantial and effective ethical guidelines within the newspaper agencies of Bangladesh, sometimes journalists become unaware and careless during reporting any issues involving children (UNICEF, 2010a).

This study showed that almost all the CSA victims were female and newspapers covering CSA stories reported in an unethical way for the female victims, compared to the males. Singh et al. (2014) conducted a review study to get the epidemiological overview of CSA where it has also concurred that females were more vulnerable to CSA across the world due to the unique characteristics of the abuse itself, which indicates a great perspective of gender discrimination in violence. Again, unethical and sensationalized news coverage was frequently observed in the cases of female CSA victims; which was found both in this study and other similar studies (Haque et al., 2020; Jones et al., 2010; Merchant, 2010). In some countries, it is strongly discouraged to publish the identity of minor and female victims in newspapers (Mike and Norris, 1997; Peter, 2002). In Bangladesh (UNICEF, 2010a), news stories unethically featured girls where they are the victims of sexual and physical abuses, suicide, and acid attack. However, gender-biased unethical reporting was manifested more in newspapers, whereas TV news was free from gender stereotyping (UNICEF, 2010a).

Public health issues like CSA are heavily dominated by episodic coverage, compared to thematic or opinion-based coverage (Major, 2009; Weatherred, 2017). This study demonstrated similar results, with a higher prevalence of unethical reporting among the episodic stories. The plausible explanation is that episodic framing focuses on storytelling by presenting an issue or information as it relates to a specific incident or person. So there lies a great chance of disclosing the identity of the person or detailed description of the incident. On the other hand, thematic framing places the issue in a larger societal context and makes people aware of specific health or social problem (Weatherred, 2017). Eventually, the chance of unethical reporting in thematic coverage is comparatively low. Again, the study of Jones et al. (2010) indicated that stories on child fatalities usually included information that identified victims, mostly the victim's full name. This was also reflected in our study.

While investigating the associated risk factors of unethical reporting in episodic news coverage, this study found that the identities of older child victims (13 years and up) were revealed more frequently than those of younger ones. This finding is likely related to the greater rates of sexual abuse among older child victims of Bangladesh. In support of this outcome, Jones et al. (2010) provided evidence to support this outcome, demonstrating that in the United States, the risk of disclosing victim's identity increased significantly for the younger victims (under 13 years old) when the rates of physical abuse rose among the younger ones.

Victim identifiers appear more in newspapers when the alleged perpetrator is known to the victim. Jones et al. (2010) stated that newspapers often quote the name of the accused offenders and their relationship with the victim to provide identifying information about the victim. This allows the victim to be easily identified.

The study findings suggest that victim's information has been included more in reports where the offender was a high-profile member of the society such as teachers, imams, political personalities, or celebrities. Jewkes (2004) and Greer and McLaughlin (2013) stated that when news stories involve a celebrity or high-profile community member, it becomes high on the newsworthiness scale. Besides, newspapers also increase newsworthiness by commercializing shame, retailing public emotions and outrages, and showing periodic sympathy towards the victim through political scandals (Kohm, 2009; Thompson, 2005). As stated by Jones et al. (2010), this might be why newspapers tend to publish the identity of victims when the accused perpetrator is a high-profile member of society.

During public reactions against CSA, such as mourning, arranging human chains, protesting, and processions, people typically discuss the victims, exhibit their photos, and sympathize with those victims and their families (Barefoot, 2014). When newspapers cover these reactions, there is a greater likelihood of reporting the victim's identity and providing unnecessary details about the event, as found in this study.

Though little is known about the specificities of the journalistic context, findings and discussions of this study alluded that journalists should assimilate what constitutes ethical behavior and why they should avoid circumstances in which professional standards collide with personal interests. News editors and gatekeepers should discuss the applicable ethical issues in the newsrooms before publishing any CSA stories so that the child rights are preserved and the credibility of the news agencies is improved (Elahi, 2013).

Strengths and limitations. This study investigated the present practice of ethical reporting on CSA cases in the daily newspapers of Bangladesh, which is one of the significant scientific contributions of this study. Because unethical reporting on CSA eventually exacerbates the trauma victim already experienced due to the abuse and complicates their psychological recovery. In addition, due to the breach of confidentiality and unethical reporting in newspapers, both the victim and their family members experience social embarrassment and shame, and other victims get discouraged for future disclosures of such incidents. Furthermore, the potential risk factors of unethical reporting derived from this study will assist journalists, gatekeepers, news editors, and policymakers in understanding the situations they should be aware of when covering CSA stories, as well as the special codes of conduct that must be established in every news organization.

This study has certain limitations that should be mentioned. The selected six newspapers might not be representative of all dailies with national coverage. So, the result might not be generalized. This study was conducted based on news articles published in 2017 and the reality may had been changed since then. Hence, news articles with more years could provide a clearer view of how frequently newspapers provide unethical reporting on CSA stories. Duplicate news stories were excluded 
by a lottery method where the content of the story was not given priority. Another noteworthy limitation is that this study provides a small insight into the gender perspective of news coverage. Detailed qualitative study is needed to assess how gender is treated in CSA coverage and whether child sexual abuse is considered a form of gender violence. Finally, since the prime objective of this study was to evaluate the prevalence of unethical reporting on CSA cases and the potential risk factors of such unethical coverage, no qualitative or in-depth interviews with journalists were conducted.

Recommendations for practice. Although UNICEF recommended guidelines on ethical reporting on and for the children in Bangladesh's newspapers in 2010 (UNICEF, 2010b), unethical reports are frequent in Bangladeshi newspapers. No significant change was seen between the rates of unethical reporting in the UNICEF survey and this study. The Swedish experience of banning corporal punishment against children reflects that laws and guidelines are not enough to reduce discrepancy unless there is people's awareness (Joan, 1996). So, along with the guidelines of UNICEF (2017) to decrease unethical reporting, broader awareness among journalists is required. However, based on our study findings, we are narrating some recommendations for the journalists, news editors, gatekeepers, communication experts, and policymakers, so that the unethical reporting will be checked, and by protecting children's rights, CSA cases will be properly reported.

First, every news organization should form its own board of directors comprised of senior journalists, editors, gatekeepers, communication experts, and policymakers to develop a code of conduct matched with existing national and UNICEF (2017) recommendations, particularly for children. In addition, every news outlet should modify its organizational objectives and procedures to focus on protecting children's well-being and rights, rather than attracting public interest, for all crimes against children, not only sex crimes.

Second, the propensity to disclose any victim's identifying information needs to be restrained during covering CSA stories. In these cases, 'pseudo name' for victims can be used. Any unworthy details of the victim's family members, professional status (like the student of ' $x$ ' class or ' $y$ ' school), and their relationship with (alleged) perpetrators (if any) should not be disclosed in news stories. Furthermore, identifying the victims' information can be disclosed if the information may help the community understand the nature of various crimes and their dynamics. However, when community safety needs are an issue, newspapers need to have the policy to determine the necessary but minimal identifying information.

Third, the description of any public reaction coverage (mourning, strike, processions, public speech, or any other reactions) against that crime should be handled with extra caution; as there is still a chance of revealing the victim's identity through the photos of banners or leaflets of public mourning or processions. Furthermore, to protect the victims and their identifications in these instances, media outlets would need to modify and upgrade their practices of always displaying victim's pictures or citing the direct quotes of public speech.

Fourth, if any CSA events involved pornography (video or picture taking of that crime scene) sharing via the internet, social media, or electronic devices, journalists should not cover details on how, by whom, or whose video or picture was captured, along with how and from which account (in case of social media) that content was leaked.

Fifth, each news agency needs to establish a specific editorial body whose main task would be to encourage journalists to cover more thematic news stories on CSA cases than episodic events, and to emphasize some aspects, like reporters' comprehensive responsibility, avoiding unwarranted harm, respect for people's privacy, and the independence and integrity of the reporters. Concerns about displaying the pictures and identities of dead bodies would necessitate extra consideration. The dead's dignity, as well as the consequences of grisly or unpleasant photographs or images, would need to be properly considered before publication.

Finally, news agencies, media experts, and policymakers should organize a half-yearly or yearly training program and performance appraisal for journalists (both local and national) which should be a constant activity. The training programs should contain workshops on basic media ethics and the basic needs for the news stories, such as accuracy and truth-seeking, proper source of information, verification, attribution, unbiasedness and fairness, balance, clarity and readability, good taste, and presenting stories by preserving human rights. Examining journalist's own perspectives and preconceptions should be another part of workshops and brainstorming. These workshops should promote awareness about how the unethical coverage of sensitive issues can affect the child victims involved in stories, as well as on the children in the audience. On the other hand, in performance appraisal programs, news agencies should thoroughly evaluate the performance of the journalists based on ethical guidelines. If any journalists are caught doing unethical reporting, the authorities should warn and offer them further training seasons.

\section{Conclusion and further direction}

This study has demonstrated that unethical reporting, especially disclosing victims' identity and detailed reporting sensationally, appeared in news articles with considerable regularities. Such unethical coverage could increase a victim's sense of shame and anxiety, violate child rights, inhibit their recovery, and make them reluctant to report CSA incidents to the authorities. However, there is hardly any research in Bangladesh that has been undertaken yet to determine why journalists are frequently violating the existing ethical guidelines during reporting child abuse stories. Therefore, the results and recommendations of this study will indulge the relevant authorities in restructuring organizational agendas and policies to prevent further unethical reporting involving children. By portraying proper and ethical coverage on CSA cases, the culture of shame and social stigma about disclosing CSA will be diminished, victim's psychological and social burdens due to unethical reporting will be reduced, and society will thrive by standing up to further CSA incidents. Now, more qualitative research is needed where the journalistic context regarding the unethical coverage will be investigated. On the other hand, research involving in-depth interviews and psychological assessments of the CSA victims should be conducted to examine how often and to what degree the negative consequences occur due to such unethical coverage. The findings of those research should be addressed and disseminated not only to public health specialists, but also to journalists, communication experts, child welfare specialists, victim advocates, criminal justice authorities, psychologists, human rights experts, and ethicists-so that viable action can be made within the traditions of the Bangladesh legal system and journalism community to avoid frequent unethical reporting on CSA instances.

\section{Data availability}

The datasets analyzed during this study are available in the Figshare repository, https://doi.org/10.6084/m9.figshare.12317348.v1 
Received: 17 February 2021; Accepted: 26 July 2021;

Published online: 16 August 2021

\section{References}

Ayre P (2001) Child protection and the media: lessons from the last three decades. Bri J Soc Work 31(6):887-901

Bangladesh Press Council (2002) Code of Conduct 1993 (2002 as amended). https://accountablejournalism.org/ethics-codes/Bangladesh-Press-Council

Barefoot A (2014) Victim Blaming, Protests, and Public Space: News Coverage of the Occupy Wall Street Sexual Assaults [Theses, Dissertations, and Other Capstone Projects, Minnesota State University-Mankato]. Paper 288. https:// cornerstone.lib.mnsu.edu/cgi/viewcontent.cgi?referer $=$ https:// scholar.google.com $/ \&$ httpsredir $=1$ \&article $=1287 \&$ context $=$ etds

Barth J, Bermetz L, Heim E, Trelle S, Tonia T (2013) The current prevalence of child sexual abuse worldwide: a systematic review and meta-analysis. Int J Public Health 58(3):469-483. https://doi.org/10.1007/s00038-012-0426-1

Bengtsson M (2016) How to plan and perform a qualitative study using content analysis. Nursing Plus Open 2:8-14. https://doi.org/10.1016/ j.npls.2016.01.001

Blanchet T (1996) Lost innocence, stolen childhoods. The University Press Limited (UPL)

Caple H (2018) News values and newsworthiness. Oxford Research Encyclopedia of Communication. https://oxfordre.com/communication/view/10.1093/ acrefore/9780190228613.001.0001/acrefore-9780190228613-e-850

Cheit RE (2003) What hysteria? A systematic study of newspaper coverage of accused child molesters. Child Abuse Neglect 27(6):607-623. https://doi.org/ 10.1016/s0145-2134(03)00108-x

Chermak SM (1994) Body count news: How crime is presented in the news media. Justice Quart 11(4):561-582. https://doi.org/10.1080/07418829400092431

Chilton JM (2012) Shame: a multidisciplinary concept analysis. J Theory Construct Testing 16:1

Choudhry V, Dayal R, Pillai D, Kalokhe AS, Beier K, Patel V (2018) Child sexual abuse in India: a systematic review. PLoS ONE 13(10). https://doi.org/ 10.1371/journal.pone.0205086

Christians CG, Glasser TL, McQuail D, Nordenstreng K, White RA (2009) Normative Theories of the Media: Journalism in Democratic Societies. University of Illinois Press

Collings SJ (2002) The impact of contextual ambiguity on the interpretation and recall of child sexual abuse media reports. J Interpersonal Violence 17(10):1063-1074. https://doi.org/10.1177/08862605-0201710-03

Consultation on Child Abuse Prevention (1999: Geneva, S., World Health Organization. Violence and Injury Prevention Team, \& Global Forum for Health Research (1999). Report of the Consultation on Child Abuse Prevention, 2931 March 1999, WHO, Geneva. WHO/HSC/PVI/99.1. WHO IRIS. https:// apps.who.int/iris/handle/10665/65900

Department of Films and Publications (2016) দশেরে মডিয়ি তালকিাভুকত পত্রপতরকি।র পরসিংখযান= [Statistics of Listed Newspapers and Periodicals in the Country] Dhaka. Department of Films and Publications, Information Ministry of Bangladesh. http://www.dfp.gov.bd

Dorfman L, Wallack L, Woodruff K (2005) More than a message: framing public health advocacy to change corporate practices. Health Educ Behav 32(3):320-336. https://doi.org/10.1177/1090198105275046. discussion 355-362

Elahi M (2013) They are not different from others: ethical practices and corruption in Bangladeshi journalism. J Mass Media Ethics 28(3). https://doi.org/ $10.1080 / 08900523.2013 .798137$

Foley M, Hayes N, O'Neill B (2008) Children's Rights and Journalism Practice: A Rights-based Perspective [An educational resource developed for UNICEF (Regional Office CEE/CIS, Geneva)]. UNICEF. https://arrow.tudublin.ie/ cseroth $/ 32$

Furedi A (1997) Sex sells, and under age sex sells even more. BMJ 314(7081):686

Goonasekera A (2001) Children in the News: reporting of children's issues in television and the press in Asia. Asian Media Communication and Information Centre

Government of Pakistan and UNICEF Pakistan (2017) Situation analysis of children in Pakistan. (p. 200). https://www.unicef.org/pakistan/media/596/file/ Situation\%20Analysis\%20of\%20Children\%20in\%20Pakistan.pdf

Greer C, McLaughlin E (2013) The Sir Jimmy Savile scandal: child sexual abuse and institutional denial at the BBC. Crime Media Culture 9(3):243-263. https:// doi.org/10.1177/1741659013513782

Haque MA, Janson S, Moniruzzaman S, Rahman AKMF, Islam SS, Mashreky SR, Eriksson U-B (2020) Child maltreatment portrayed in Bangladeshi newspapers. Child Abuse Rev 29(5):448-462. https://doi.org/10.1002/car.2606

Ho GWK, Chan ACY (2018) Media portrayal of a hidden problem: an analysis of Hong Kong newspaper coverage of child maltreatment in 2016. Child Abuse Neglect 83:62-73. https://doi.org/10.1016/j.chiabu.2018.07.002
Hodgkiss M (2017) Newsworthiness guidelines for a socially responsible press: aligning definitions at the intersection of journalism, ethics, and the law. Communication Dissertations. https://scholarworks.gsu.edu/communication_diss/88

Human Rights Watch (2013) Breaking the Silence: Child Sexual Abuse in India. https:// www.hrw.org/report/2013/02/07/breaking-silence/child-sexual-abuse-india

IFJ (2001) Children's Rights and Media: Guidelines and Principles for Reporting on Issues Involving Children (Articles 42-54: Implementation and Monitoring) [Training Materials]. International Federation of Journalists. https:// archive.crin.org/en/library/publications/childrens-rights-and-mediaguidelines-and-principles-reporting-issues-involving.html

Itaoka K (2012) Regression and Interpretation Low R-squared. Proceedings of the presentation at Social Research Network 3rd Meeting, Noosa. Mizuho Information and Research Institute, Inc.

Jaggi R, Majumdar P (2009) Popularity vs. credibility: an analysis of public perception of sensationalism in Indian television news. IMS Manthan. J Manag Comput Sci Journal 4(2):171-179

Jewkes Y (2004) Media and crime. Sage. https://uk.sagepub.com/en-gb/eur/mediaand-crime/book 240940

Joan ED (1996) The Swedish Ban on Corporal Punishment: Its History and Effects. Family Violence Against Children: A Challenge for Society (pp. 19-25) Walter de Gruyter \& Co

Jones LM, Finkelhor D, Beckwith J (2010) Protecting victims' identities in press coverage of child victimization. Journalism 11(3):347-367. https://doi.org/ $10.1177 / 1464884909360925$

Kohm SA (2009) Naming, shaming and criminal justice: Mass-mediated humiliation as entertainment and punishment. Crime Media Culture 5(2):188-205. https://doi.org/10.1177/1741659009335724

Lonne B, Parton N (2014) Portrayals of child abuse scandals in the media in Australia and England: impacts on practice, policy, and systems. Child Abuse Neglect 38:822-836

Maharani P (2018) Portraying the multitudes: representation of identities of sexual minorities on Indonesia-based feminist web magazine Magdalene.co. J Southeast Asian Human Rights 2(2):358-388. https://doi.org/10.19184/jseahr.v2i2.5645

Major LH (2009) Break it to me harshly: The effects of intersecting news frames in lung cancer and obesity coverage. J Health Communtion 14(2):174-188. https://doi.org/10.1080/10810730802659939

McQuail D (2010) McQuail's Mass Communication Theory. SAGE

Mejia P, Cheyne A, Dorfman L (2011) Case by Case: news coverage of child sexual abuse, 2007-2009.

Merchant R (2010) Who are abusing our children? An exploratory study on reflections on child abuse by media commentators. Doctoral Dissertation. Massey University. https://mro.massey.ac.nz/bitstream/handle/10179/1612/ 01_front.pdf?isAllowed $=y \&$ sequence $=3$

Mike J, Norris B (1997) Information-Childs-Rights-International-Survey.pdf (International Survey of Journalistic Standards Established for Reporting Children's Issues). International Federation of Journalists; e Media Wise. http://www.mediawise.org.uk/wp-content/uploads/2011/03/InformationChilds-Rights-International-Survey.pdf

Miller-Perrin CL, Perrin RD (2012) Child maltreatment: an introduction. SAGE

Nair P (2019) Child sexual abuse and media: coverage, representation and advocacy. Institutionalised Children Explorations and Beyond 6(1):38-45

National Center for Injury Prevention and Control (2016) Suggested practices for journalists reporting on child abuse and neglect. Division of Violence Prevention. https://www.cdc.gov/violenceprevention/pdf/childmaltreatment/journalistsguide.pdf

Niner S, Ahmad Y, Cuthbert D (2013) The 'social tsunami': media coverage of child abuse in Malaysia's English-language newspapers in 2010. Media Culture Soc 35(4):435-453. https://doi.org/10.1177/0163443713483796

Peter M (2002) Child rights and the media. Putting children in the right. International Federation of Journalists. https://resourcecentre.savethechildren.net/ library/child-rights-and-media-putting-children-right

Saint-Jacques M-C, Villeneuve P, Turcotte D, Drapeau S, Ivers H (2012) The role of media in reporting child abuse. J Soc Service Res 38(3):292-304. https:// doi.org/10.1080/01488376.2011.627232

Schildkraut J (2017) Crime news in newspapers. Oxford Research Encyclopedia of Criminology and Criminal Justice

Schwarz A (2006) The theory of newsworthiness applied to Mexico's press. How the news factors influence foreign news coverage in a transitional country. Communications 31(1):45-64. https://doi.org/10.1515/COMMUN.2006.004

Singh MM, Parsekar SS, Nair SN (2014) An epidemiological overview of child sexual abuse. J Fam Med Primary Care 3(4):430-435. https://doi.org/10.4103/ 2249-4863.148139

Strömbäck J, Karlsson M, Hopmann DN (2012) Determinants of news content. Journal Stud 13(5-6):718-728. https://doi.org/10.1080/1461670X.2012.664321

Thompson JB (2005) The new visibility. Theory Culture Soc 22(6):31-51. https:// doi.org/10.1177/0263276405059413

Treadwell P (2006) Child abuse by television: have we resigned from UNCROC. New Zealand Family Law J 5:103-104 
UN General Assembly (1989) Convention on the Rights of the Child (No. 1577; Treaty Series, p. 3). United Nations. https://downloads.unicef.org.uk/wp-content/ uploads/2016/08/unicef-convention-rights-child-uncrc.pdf?_ga=2.32583742. 1635492913.1579331219-1540420562.1579331219

UNICEF (2010a) Baseline Study: Children in Bangladesh News Media (Building Capacity of Journalists on Ethical Reporting on Children, p. 129). UNICEF, Management and Resources Development Initiative (MRDI). https:// www.mrdibd.org/publications/UNICEF_Ethical_Reporting_Children.pdf

UNICEF (2010b) Children in Bangladesh News Media: Follow-Up Study (Building Capacity of Journalists on Ethical Reporting on Children, p. 169). UNICEF, Management and Resources Development Initiative (MRDI). https:// www.mrdibd.org/publications/Unicef_Follow_Up_Study_Report.pdf

UNICEF (2014) Thai media continues to violate children's rights, including the regular disclosure of the identify of child victims. UNICEF. https:// www.unicef.org/thailand/media_23282.html

UNICEF (2017) Guidelines for Reporting on Children (p. 6). https:// www.unicef.org/cambodia/media/1426/file/A\%20guideline\%20for\% 20journalists\%20on\%20reporting\%20on\%20children_Eng.pdf\%20.pdf

Weatherred JL (2017) Framing child sexual abuse: a longitudinal content analysis of newspaper and television coverage, 2002-2012. J Child Sexual Abuse 26(1):3-22. https://doi.org/10.1080/10538712.2016.1257528

Wong JS, Lee C (2021) Extra! extra! the importance of victim-offender relationship in homicide newsworthiness. J Interpersonal Violence 36(9-10):4186-4206. https://doi.org/10.1177/0886260518789142

\section{Acknowledgements}

We are thankful to M. Mithun Miya, Assistant Professor, Department of Mass Communication and Journalism, Jagannath University, Dhaka, and Anika Anjum, Research Assistant, BSMMU for their unconditional help during data collection and coding.

\section{Author contributions}

MAH and AIA substantially conceptualized and designed the study. MAH supervised the study. AIA collected, curated, analyzed, and interpreted the data, and wrote the draft manuscript. AIA revised the manuscript with important intellectual input from all authors. All authors commented on and finally approved the final manuscript to be published.

\section{Competing interests}

The authors declare no competing interests.

\section{Additional information}

Supplementary information The online version contains supplementary material available at https://doi.org/10.1057/s41599-021-00880-0.

Correspondence and requests for materials should be addressed to A.I.A. or MA.H.

Reprints and permission information is available at http://www.nature.com/reprints

Publisher's note Springer Nature remains neutral with regard to jurisdictional claims in published maps and institutional affiliations.

(c) (i) Open Access This article is licensed under a Creative Commons Attribution 4.0 International License, which permits use, sharing adaptation, distribution and reproduction in any medium or format, as long as you give appropriate credit to the original author(s) and the source, provide a link to the Creative Commons license, and indicate if changes were made. The images or other third party material in this article are included in the article's Creative Commons license, unless indicated otherwise in a credit line to the material. If material is not included in the article's Creative Commons license and your intended use is not permitted by statutory regulation or exceeds the permitted use, you will need to obtain permission directly from the copyright holder. To view a copy of this license, visit http://creativecommons.org/ licenses/by/4.0\%

(c) The Author(s) 2021 